\title{
Occupational exposure limits for chemicals in the European Union
}

\author{
W J Hunter, G Aresini, R Haigh, P Papadopoulos, W Von der Hude
}

Exposure limits for dangerous substances in working environments have played a major part in the control of occupational disease. Exposure limits are quantitative health standards expressed as mean concentrations over a given period which an environmental pollutant must not exceed if the exposed workers' health is not to be affected. This is true provided the term limit is not accompanied by adjectives such as acceptable or tolerable, which imply the general social acceptability of a particular risk or general biological tolerance of an exposure.

It is obvious that acceptable cannot be applied on the basis of a decision taken by scientists alone; it implies evaluation both of the health effect and any other socioeconomic or political factor implied in a decision of this nature. The term tolerable makes no biological sense in that each subject tends to respond to an exogenous nuisance in a personal way, as a function of numerous individual factors. Thus, a certain level of exposure may well be tolerated (the internal environment remains in equilibrium) by one subject and not by another. For these reasons the current scientific trend is to exclude these two adjectives in the context of exposure limits; in 1977 the International Labour Organisation (ILO) defined an exposure limit as:

"... the concentration in air of a harmful substance which, if the standards are respected, does not generally have harmful effects-including long-term effects on posterity-on the health of workers exposed for 8 to 10 hours a day, 40 hours a week; this exposure is considered acceptable by the competent authority which determines the limits, but it is possible that it may not completely guarantee the protection of the health of all the workers; accordingly, the exposure limit does not constitute an absolute dividing line between harmless and harmful concentrations, but is intended solely as a guide to prevention".

In fact, verification that a specific chemical or physical agent does not exceed the exposure limits laid down for working environments (a fundamental and often decisive aspect in the prevention of occupational diseases) is today only one factor in assessing good practice in industrial hygiene, and does not signify biological compatibility for all exposed people. Thus when the results of environmental monitoring have to be compared with reference values, it is essential also to take account of other factors which influence exposure and of different biological conditions if we are not to lose sight of the ultimate objective of prevention.

\section{Approach of the European Union}

The main role of the exposure limits in the control and prevention of occupational diseases has been recognised by the European Communities since the adoption of the first action programme on the health and safety at work in $1978,{ }^{1}$ with a subsequent inclusion of relevant terminology in the community legislation on the use of chemicals at work.

The first comprehensive framework for Community legislation on chemicals in the workplace was included in Council Directive $80 / 1107 / \mathrm{EEC}^{2}{ }^{2}$ which set out measures for the control of risks related to chemical, physical, and biological agents. It was amended in 1988 by the adoption of Directive $88 / 642 / \mathrm{EEC}^{3}{ }^{3}$ which emphasised the mechanisms for setting exposure limits for hazardous chemicals. Furthermore Council Directive 90/394/EEC on carcinogens at work ${ }^{4}$ defines carcinogens in relation to the criteria set up under the framework of Council Directive 67/548/EEC, ${ }^{5}$ and contains a particular provision for setting up limit values for carcinogens.

The concept embodied in these Directives of having two different types of exposure limits was agreed by the Council of Ministers: (a) "binding limit value", adopted by the Council under the procedure laid down in Article 118a of the Treaty; reflects scientific data as well as socioeconomic considerations and must be transposed into national legislation as a minimum requirement, and $(b)$ "indicative limit value", adopted by the Commission after obtaining the opinion of a committee consisting of representatives of the Member States and presided over by a representative of the Commission; an indicative limit value reflects expert evaluations based on scientific data; national authorities shall take indicative limit values into account, among other things, when they adopt national measures for the protection of workers.

These limit values are stated as the eight hour time weighted average ( $8 \mathrm{~h}$ TWA) concentration for exposure of a substance in gaseous, vaporous, or suspended form in the air at the workplace, whereas exposure means the presence of a chemical agent in the air within the breathing area of a worker.

Community legislation, which may be 
Table 1 Substances for which binding limit values or prohibition measures exit

\begin{tabular}{ll}
\hline Vinyl chloride monomer & $7 \mathrm{ppm}$ \\
Lead and its ionic compounds & \\
Asbestos & $0.15 \mathrm{mg} / \mathrm{m}^{3}$ \\
$\quad$ Chrysotile & $0.60 \mathrm{f} / \mathrm{ml}$ \\
Other forms (alone or in mixtures) & $0.30 \mathrm{f} / \mathrm{ml}$ \\
2-Napthylamine and its salts & Ban of production or use \\
4-Aminobiphenyl and its salts & Ban of production or use \\
Benzidine and its salts & Ban of production or use \\
4-Nitrodiphenyl & Ban of production or use \\
\hline
\end{tabular}

Table 2 Substances for which indicative limit values exist due to Commission Directive 91/322/EEC ${ }^{10}$

\begin{tabular}{|c|c|c|c|}
\hline \multirow[b]{2}{*}{ Substance } & \multirow[b]{2}{*}{$C A S^{\star}$} & \multicolumn{2}{|c|}{ Limit valuest } \\
\hline & & $m g / m^{3} \ddagger$ & $p p m \S$ \\
\hline Nicotineף & $54-11-5$ & 0.5 & - \\
\hline Formic acid & $64-18-6$ & 9 & 5 \\
\hline Acetic acid & $64-19-7$ & 25 & 10 \\
\hline Methanol & $67-56-1$ & 260 & 200 \\
\hline Acetonitrile & $75-05-8$ & 70 & 40 \\
\hline Picric acid $\rrbracket$ & $88-89-1$ & $0 \cdot 1$ & - \\
\hline Naphthalene & $91-20-3$ & 50 & 10 \\
\hline Nitrobenzene & $98-95-3$ & 5 & 1 \\
\hline Resorcinol & $108-46-3$ & 45 & 10 \\
\hline Diethylamine & $109-89-7$ & 30 & 10 \\
\hline Pyridinef & $110-86-1$ & 15 & 5 \\
\hline Carbon dioxide & $124-38-9$ & 9000 & 5000 \\
\hline Oxalic acidף & $144-62-7$ & 1 & - \\
\hline Cyanamide & $420-04-2$ & 2 & - \\
\hline Calcium dihydroxide $\|$ & $1305-62-0$ & 5 & - \\
\hline Disphosphorus pentoxidef & $1314-56-3$ & 1 & - \\
\hline Disphosphorus pentasulphidef & $1314-80-3$ & 1 & - \\
\hline Cresols (all isomers) & $1319-77-3$ & 22 & 5 \\
\hline Platinum (metallic) $\|$ & $7440-06-4$ & 1 & - \\
\hline Lithium hydridef & $7580-67-8$ & 0.025 & - \\
\hline Bromine & $7726-95-6$ & 0.7 & $0 \cdot 1$ \\
\hline Phosphorus pentachloridef & $10026-13-8$ & 1 & - \\
\hline Nitrogen monoxide & $10102-43-9$ & 30 & 25 \\
\hline Pyrethrum & $8003-34-7$ & 5 & - \\
\hline Barium (soluble compounds as $\mathrm{Ba}$ ) & - & 0.5 & - \\
\hline Silver (soluble compound as Ag) & - & 0.01 & - \\
\hline Tin (inorganic compounds as Sn) & - & 2 & - \\
\hline
\end{tabular}

${ }^{\star}$ CAS $=$ chemical abstract service number.

†Measured or calculated in relation to a reference period of eight hours ( $8 \mathrm{hTWA}$ ).

$\neq \mathrm{mg} / \mathrm{m}^{3}$ Of air at $20^{\circ} \mathrm{C}$ and $101,3 \mathrm{KPa}(760 \mathrm{~mm}$ mercury pressure)

ppm = Parts per million by volume in air $\left(\mathrm{ml} / \mathrm{m}^{3}\right)$

TExisting scientific data on health effects seem to be particularly limited.

amended by the Council, requires already that binding limit values be fixed for certain chemicals (appendix 1). After a similar procedure, specific Council Directives ${ }^{6-9}$ have laid down binding limit values or prohibition measures for the chemicals (table 1). Apart from the groups of chemicals for which binding limit values may be specified, the Commission is empowered to fix "indicative limit values". Table 2 shows the chemicals for which indicative limit values have been adopted in Commission Directive 91/322/EEC. ${ }^{10}$

\section{Scientific basis for exposure limits}

Despite the different concepts sometimes encountered, there is nowadays a general agreement on the methods and variables to be used in laying down exposure limits at work. Despite the acknowledgement of the need for more standardised toxicological and epidemiological studies to provide the scientific basis for the proposals for health based exposure limits for the working environment, minimum data have been identified on: (a) the physical and chemical properties of the substance under investigation, including the quality and quantity of impurities; (b) the results of studies of acute, subacute, short term, and chronic toxicity (through the airways, stomach, and skin; of animals or humans). Information on genotoxicity, sensitisation, and reproductive toxicity should be taken into consideration, when available.

The first task in evaluating the available data is the identification of a no observed adverse effect level (NOAEL). However, whenever the only data available are those derived from animal experiments, it is essential, for various reasons, to introduce a factor by which the observed non-effect dose is divided. It should be stressed that in choosing and applying the final figure, the factor should only take human health into consideration. This procedure is a cornerstone of quantitative, environmental, and industrial toxicology. Nevertheless, it is on the basis of the NOAEL that the factors can be applied and thus it is necessary to find this level to suggest an appropriate dose.

As far as carcinogens are concerned, in the light of present knowledge the scientific community does not recognise the existence of a dose for carcinogens below which we can be certain that cancer will not occur. Molecular biology has amply shown the persistent existance of chemical carcinogens which can damage DNA so that it is not possible to postulate a threshold dose that would have no genotoxic effect. Neither does epidemiology provide evidence of a zero risk of tumours. Even if it can be said for a given cohort of workers exposed that there is no significant increase in the incidence of cancer, it is easy to argue that every working situation is specific and concerns specific groups of workers.

A different problem, but one that has identical practical implications, concerns the possibility of proposing exposure limits for substances which cause sensitivity. The observance of the exposure limits is not sufficient to protect people who are sensitised to the specific substance used at work; however, it is known that the lower the exposure to chemicals with sensitising capacity, the smaller the number of workers who will develop allergic syndromes.

\section{Scientific Committee for Occupational Exposure Limits to Chemical Agents (SCOEL)}

In 1990, at the request of the Council, the European Commission had set up an informal group of scientists, known as the Scientific Expert Group (SEG), to give advice on setting limit values, after having reviewed the different approaches in the member states. To encourage the work to develop harmonised occupational exposure limits (OELs), the European Commission decided to formalise the SEG and with its Decision of 12 July $1995^{11}$ has set up a formal base for the work on the scientific evaluation of the risk at the workplace related to chemical substances. The Committee formed comprises not more than 21 members drawn from all member states and reflects the full range of scientific expertise which is necessary to fulfil its mandate, including, in particular chemistry, toxicology, epidemiology, occupational medicine, industrial hygiene, and gen- 
Table 3 Key principles agreed by SCOEL

Strategy for short term exposure

Strategy to apply uncertainty factors

Strategy for assigning a skin notation

Interpretation of neurobehavioural studies

Reproductive toxicity

Assessment of sensitiser

Biological limit values

$8 \mathrm{~h}$ TWA exposure limits

Role of the SCOEL in the evaluation of chemical carcinogens

eral competence in setting OELs

Article 2 of the Decision describes the key issues of the major task of the SCOEL:

"The Committee shall in particular give advice on the setting of OELs based on scientific data and where appropriate shall propose values which may include:

the eight-hour time weighted average (TWA);

short-term/excursion limits (STEL);

biological limit values"

To take into account specific problems "the OELs may be supplemented, as appropriate, by further notations' and " the committee shall advise on any other absorbtion of the substance in question via other routes".

It has already become clear that several key principles concerning the criteria of setting OELs need to be discussed in detail because already existing national scientific committees have applied different approaches to develop their limit values. This was influenced on the one hand by different historically developed legislation and on the other hand by the fact that not only one truth can be interpreted from several scientific data.

The SCOEL has considered these differences and started a fruitful discussion on their principles to fulfil the requirements of the European legislation. They have already agreed on some key principles which will be published in brief documents (table 3 ).

It is well understood that not all aspects of debate can be discussed at once, furthermore, the development in science underlies rapid changes. This means that also in future the SCOEL will consider this dynamic process and will further go on discussing other key principles of the procedure to set OELs.

\section{Procedure for the establishment of limit values in the European Union}

The scientific reliability of the SCOEL recommendations is the cornerstone for any of the Commission's legislative proposals to set limit values for chemicals. It was soon recognised that a procedure for the adoption of OELs generally acceptable to all interested groups would be of great importance, it will facilitate the work of the Commission and it will minimise or even eliminate the negative scientific critisism of the figures decided by the SCOEL.

For this reason in 1994, after an extensive consultation of the tripartite Advisory Committee for Safety, Hygiene, and Health Protection at Work (ACSHH), the Commission approved a Guidance note (as an internal working document) on procedures to set limit values, which is to be updated in the light of experience. This Guidance note sets out the arrangements for the scientific review and evaluation for establishing OELs in the European Union. It includes the procedure to be followed and how, and at what stage, the interested parties (government, industry, workers, the scientific community, and other relevant organisations) can make their contribution to this procedure.

Table 4 summarises the main stages of the process. Whereas the first three stages are mainly related to the scientific evaluation which concerns the work of the SCOEL, the subsequent stages are more related to the work carried out by the European Commission, and non-scientific matters have also to be considered. The SCOEL starts its work by evaluating criteria documents from different sources. These criteria documents should contain all available information and should fit with a format described in the guidelines for the preparation of criteria documents. ${ }^{12}$ The identified base document is announced by the Commission through publication in the Official Journal with the request for further data, especially unpublished, to be provided to the Commission, to guarantee the completeness of the data for the chemical agent concerned.

The SCOEL evaluates the scientific dossier and the suplementery data for the identification of the critical health effects. The detailed evaluation of the key studies describing them, leads to a short document which describes the recommended OELs and the recommendation is supported and explained by information on the basic data, a description of the critical effect, the extrapolation techniques used, and any data on possible risks to human health. The technical feasibility of monitoring exposure is also noted. Furthermore the SCOEL decided to identify important gaps in the data and need for more research.

Once the summary document is agreed by the Committee the Commissiom makes it public to interested parties with the request for health based scientific comments and eventually further data. After a comments period of about six months the SCOEL rediscusses the document in the light of the comments received and adopts the final version which is then published by the Commission.

By applying this procedure, recommendations of more than 50 OELs have been made to the Commission (appendix 2). The experience on this work has shown that a process clear to the member states of the European Union and the social partners is a good way forward, although not all recommendations

\section{Table 4 Stages leading to the establishment of OELs}

Stage 1 Preparation of a scientific dossier for review

Stage 2 Evaluation of scientific dossier

Stage 3 Development of recommendation from the SCOEL to the Commission services for a scientifically based OEL

Stage 4 Development of proposal for an OEL by the Commission services

Stage 5 Consultation of the Advisory Committee for Safety, Hygiene, and Health Protection at Work

Stage 6 Adoption of the implementing Directive 
are welcomed unanimously by all interested parties. In this context it should be stressed that the primary task of the SCOEL is the recommendation of a health based OEL.

Once the Commission services have received recommendations from the SCOEL they are in a position to develop legal proposals for OELs. At this stage and according to the type of the OEL, the Commission services will seek relevant technical and socioeconomic data. If any of the interested parties is aware that there are such data which can be shown to be pertinent to the development of a Commission's proposal then these should be made known to the Commission services.

The Commission's proposal for a legislative text is submitted to the ACSHH. At this stage all the interested parties have a further opportunity, through the ACSHH structure, to contribute to the opinion adopted by the Committee. The opinion delivered by the ACSHH is available through its minutes, and is also published in the ACSHH's annual report. Once these consultations have been completed the Commission services will finalise their preparation of a proposal to be agreed by the Commission. According to the type of OEL and the legal procedure selected, further consultation on the Commission's proposal, within the appropriate European Union institutions, will take place, before the final adoption and publication in the Official Journal of an OEL.

\section{Future work}

In 1995 the Commission adopted a Communication on a programme concerning safety, hygiene, and health at work (1996-2000)..$^{13}$ The programme underlines the need for further action in setting limit values, through the formalisation of SCOEL and the continuation of the efforts for adoption by the Council of the Commission's proposal for a Directive on chemical agents. ${ }^{14}$

As far as the legislative action is concerned, the Commission intends to carry out the following proceedures.

(1) To push for progress on the proposal for chemical agents pending now at Council level. This proposal has been developed to provide an opportunity for consolidating and simplifying old legislation on chemicals, and to bring the existing measures up to date in respect of the social aspects of the internal market and relations with the Community's trading partners and to fulfil international obligations, especially after the conclusions of the United Nations concerns on environment and development (UNCED).

The new Directive will be an individual Directive under the Framework Directive $89 / 391 / \mathrm{EEC}^{15}$ and intends to amplify the Framework Directive's general provisions by: (a) establishing minimum requirements specifically identified for the protection of workers against risks to their health and safety arising from any chemical agent at work; (b) consolidating, clarifying, updating, and adapting existing provisions on chemical agents in the workplace in the light of current knowledge and aligning them with Directive 89/391/EEC; $(c)$ ensuring that all precautionary measures at work are based on a proper assessment of risks arising from the way workers are exposed to chemical agents and that by taking account of the features of the workplace, the activity and likely exposure protection measures properly reflect the scale of risk without imposing unnecessary burdens on employers.

The concept of having two different types of occupational exposure levels, of different status, is retained from Directive 80/1107/EEC. ${ }^{2}$

(2) To make proposals for legislation concerning indicative limit values for chemicals, based on the existing recommendations of SCOEL (appendix 2).

(3) To push for progress to the Commission's proposal amending the carcinogens Directive 90/394/EEC, ${ }^{16}$ where a binding limit value of $1 \mathrm{ppm}$ for benzene is proposed.

The Commission, in cooperation with the $\mathrm{ACSHH}$, has already developed an agreed open list (appendix 3) of chemical agents where there is major concern at the workplace. The SCOEL new recommendations for OELs of many chemicals are expected.

The advantages of a common European approach to the process for setting limit values are obvious. The enormous effort necessary to evaluate toxicological data should not be duplicated. The Commission has access to the results of several data reporting programmesfor example, risk assessment for existing substances and risk assessment for pesticides-which are carried out under European legislation, unpublished data from all European industries can be considered, and cost sharing for the development of urgently needed data on a European level is promoted.

Appendix 1 Substances for which binding limit values may be established

PART 1

Acrylonitrile

Asbestos

Arsenic and compounds

Benzene

Benzene an compounds

Cadmium and compounds

Mercury and compounds

Nickel and compounds

Lead and compounds
Chlorinated hydrocarbons:

Chloroform

Paradichlorobenzene

PART 2

Carbon tetrachloride

Carcinogens

(a) Substance to which, in Annex I to Directive $67 / 548 / E^{2} C^{5}$ the risk-phrase R 45 "may cause cancer" is applied

(b) Preparation which, under Article 3(5)(j) of Directive $88 / 379 / \mathrm{EEC}^{17}$ must be labelled as R 45 "may cause cancer"

(c) Substance, preparation, or a process referred to in Annex I to Directive $90 / 394 / \mathrm{EEC}^{4}$ as well as a substance or I to Directive $90 / 394 / \mathrm{EEC}$ as well as a substance or preparation released by a process referred to in Ann includes:

1 Manufacture of auramine

2 Work involving exposure to aromatic polycyclic hydrocarbons present in coal soots, pitch, fumes,

3 Work involving exposure to dusts, fumes, and sprays produced during the roasting and electrorefining of cupronickel mattes

4 Strong acid process in the manufacture of isopropyl alcohol 
Appendix 2 Substances for which SCOEL has made recommendations

\begin{tabular}{|c|c|c|c|c|c|c|}
\hline \multirow[b]{2}{*}{ Substance } & \multirow[b]{2}{*}{$C A S$} & \multicolumn{2}{|c|}{$8 h T W A$} & \multicolumn{2}{|l|}{$S T E L^{\star}$} & \multirow[b]{2}{*}{ NOT } \\
\hline & & $p p m$ & $m g / m^{3}$ & $p p m$ & $m g / m^{3}$ & \\
\hline Acetone & $67-64-1$ & 500 & 1210 & - & & - \\
\hline Allyl alcohol & $107-18-6$ & 2 & $4 \cdot 8$ & 5 & $12 \cdot 1$ & Skin \\
\hline Ammonia & $7664-41-7$ & 20 & 14 & 50 & 36 & - \\
\hline Amylacetate, tert- & $625-16-1$ & 50 & 270 & 100 & 540 & - \\
\hline Benzene & $71-43-2$ & RA $\ddagger$ & & - & & Skin \\
\hline Butanone, 2- & $78-93-3$ & 100 & 300 & - & & - \\
\hline Butoxyethanol, 2- & $111-76-2$ & 20 & 98 & - & & Skin \\
\hline Butoxyethyl acetate, 2 & $112-07-2$ & 20 & 134 & - & & Skin \\
\hline Butylacrylate, n- & $141-32-2$ & 2 & 11 & 10 & 53 & - \\
\hline Carbon monoxide & $630-08-0$ & 20 & 23 & 100 & 117 & - \\
\hline Carbon tetrachloride & $56-23-5$ & 1 & $6 \cdot 4$ & 5 & 32 & Skin \\
\hline Chlorodifluoromethane & $75-45-6$ & 1000 & 3600 & - & & - \\
\hline Chloroform & $67-66-3$ & 2 & 10 & - & & Skin \\
\hline Cumene & $98-82-8$ & 20 & 100 & 50 & 250 & Skin \\
\hline Cyclohexane & $110-82-7$ & 50 & 175 & - & & \\
\hline Cyclohexanone & $108-94-1$ & 10 & $40 \cdot 8$ & 20 & $81 \cdot 6$ & Skin \\
\hline Dichlorobenzene, 1,2- & $95-50-1$ & 20 & 122 & 50 & 306 & - \\
\hline Dichlorobenzene, $1,4-$ & $106-46-7$ & 20 & 122 & 50 & 306 & - \\
\hline Dichloroethane, $1,1-$ & $75-34-3$ & 100 & 412 & - & & - \\
\hline Diethylether & $60-29-7$ & 100 & 308 & 200 & 616 & - \\
\hline Dimethylacetamide, $\mathrm{N}, \mathrm{N}$ - & $127-19-5$ & 10 & 36 & - & & Skin \\
\hline Dimethylamine & $124-40-3$ & 2 & $3 \cdot 8$ & 5 & $9 \cdot 4$ & - \\
\hline Dimethylether & $115-10-6$ & 1000 & 1920 & - & & - \\
\hline \multicolumn{7}{|l|}{ Dipropyleneglycol } \\
\hline monomethylether & $34590-94-8$ & 50 & 308 & - & & Skin \\
\hline Ethanolamine & $141-43-5$ & 1 & $2 \cdot 5$ & 3 & $7 \cdot 6$ & Skin \\
\hline Ethyl acetate & $141-78-6$ & 200 & 734 & 400 & 1468 & - \\
\hline Ethylamine & $75-04-7$ & 5 & $9 \cdot 4$ & - & & - \\
\hline Ethylbenzene & $100-41-4$ & 100 & 422 & 200 & 884 & Skin \\
\hline Ethylene glycol & $107-21-1$ & 10 & 26 & 20 & 52 & Skin \\
\hline Heptanone, 2- & $110-43-2$ & 50 & 238 & - & & - \\
\hline Heptanone, 3- & $106-35-4$ & 20 & 95 & - & & - \\
\hline Hexane, n- & $110-54-3$ & 20 & 72 & - & & - \\
\hline Hydrogen bromide & $10035-10-6$ & - & & 2 & $6 \cdot 7$ & - \\
\hline Hydrogen chloride & $7647-01-0$ & 5 & 8 & 10 & 15 & - \\
\hline Hydrogen selenide & $7783-07-5$ & 0.02 & $0 \cdot 7$ & 0.05 & $0 \cdot 17$ & - \\
\hline Methoxypropanol-2, 1- & $107-98-2$ & 50 & 188 & 100 & 375 & Skin \\
\hline Methoxypropylacetate-2, 1 & $108-65-6$ & 50 & 275 & 100 & 550 & Skin \\
\hline Methyl formate & $107-31-3$ & - & & - & no & Skin \\
\hline Methlheptan-3-one, 5- & $541-85-5$ & 10 & 53 & 20 & 107 & - \\
\hline Methlyhexan-2-one, 5- & $110-12-3$ & 20 & 95 & - & & - \\
\hline Methylpentan-2-one, 4- & $108-10-1$ & 20 & 83 & 50 & 208 & - \\
\hline Monochlorbenzene & $108-90-7$ & 10 & 47 & 20 & 94 & - \\
\hline Monochloroethane & $75-00-3$ & 100 & 268 & - & & - \\
\hline Nitric acid & $7697-37-2$ & - & & 0.5 & $1 \cdot 3$ & - \\
\hline Pentylacetate & $628-63-7$ & 50 & 270 & 100 & 540 & - \\
\hline Pentylacetate, 2- & $626-38-0$ & 50 & 270 & 100 & 540 & - \\
\hline Pentylacetate, 3- & $620-11-1$ & 50 & 270 & 100 & 540 & - \\
\hline Pentylacetate, iso- & $123-92-2$ & 50 & 270 & 100 & 540 & - \\
\hline Phenol & $108-95-2$ & 2 & $7 \cdot 8$ & - & & Skin \\
\hline Phosgene & $75-44-5$ & 0.02 & 0.08 & $0 \cdot 1$ & 0.4 & - \\
\hline Phosphoric acid & $7664-38-2$ & - & 1 & - & 2 & - \\
\hline Propionic acid & $79-09-4$ & 10 & 31 & 20 & 62 & - \\
\hline Silver, metallic & $7440-22-4$ & $0 \cdot 1$ & & - & & - \\
\hline Sodium azide & $26628-22-8$ & & $0 \cdot 1$ & & $0 \cdot 3$ & Skin \\
\hline Tetrahydrofuran & 109-99-9 & 50 & 150 & 100 & 300 & Skin \\
\hline Toluene & $108-88-3$ & 20 & $76 \cdot 6$ & 50 & $191 \cdot 5$ & Skin \\
\hline Trichlorobenzene, $1,2,4-$ & $120-82-1$ & 2 & $15 \cdot 1$ & 5 & $37 \cdot 8$ & Skin \\
\hline Trichloroethane, $1,1,1-$ & $71-55-6$ & 100 & 555 & 200 & 1110 & - \\
\hline Triethylamine & $121-44-8$ & 2 & $8 \cdot 4$ & 3 & $12 \cdot 6$ & Skin \\
\hline Trimethylbenzene, $1,2,3-$ & $526-73-8$ & 20 & 100 & - & & \\
\hline Trimethylbenzene, $1,2,4-$ & $95-63-6$ & 20 & 100 & - & & - \\
\hline Trimethylbenzene, $1,3,5-$ & $108-67-8$ & 20 & 100 & - & & - \\
\hline Trimethylbenzenes & 25551-13-7 & 20 & 100 & - & & - \\
\hline Xylene, $m$ - & $108-38-3$ & 20 & 221 & 100 & 442 & Skin \\
\hline Xylene, 0 & $95-47-6$ & 20 & 221 & 100 & 442 & Skin \\
\hline Xylene, $p$ & $106-42-3$ & 20 & 221 & 100 & 442 & Skin \\
\hline Xylenes, isomers & $1330-20-7$ & 20 & 221 & 100 & 442 & Skin \\
\hline
\end{tabular}

*The STEL is a limit value above which exposure should not occur and is related to a 15 minute period, unless otherwise specified.

tA skin notation assigned to the OEL identifies the possibility of significant uptake through the skin.

$\ddagger$ According to the risk assessment $8 \mathrm{~h}$ TWA should be $<1 \mathrm{ppm}$. 
1 Council Resolution of 29 June 1978 on an action programme of the European Communities on safety and health at work. Official fournal of the European Communities 1978;C165/11·7·1978:1-13.

2 Council Directive 80/1107/EEC of 27 November 1980 on the protection of workers from the risks related to exposure to chemical, physical and biological agents at work. Official fournal of the European Communities 1980; L327/3 $\cdot 12 \cdot 1980: 8-13$.

3 Council Directive 88/642/EEC of 16 December 1988 amending Directive 80/1107/EEC of 27 November 1980 on the protection of workers from the risks related to exposure to chemical, physical, and biological agents at work. Official fournal of the European Communities $1988 ; 1356 / 24 \cdot 12 \cdot 1988: 74-8$

4 Council Directive 90/394/EEC of 28 June 1990 on the protection of workers from the risks related to exposure to carcinogens at work. Official foumal of the European Communities 1990;L196/26*7·1990:1-7.

5 Council Directive 67/548/EEC of 27 June 1967 on the approximation of the laws, regulations, and administrative provisions relating to the classification, packaging, and prolling of dangerous substances. Official goumal and labelling of dangerous of the European Communities 1967;L196/16・8・1967:1. EEC. Official fournal of the European Communities EEC. Official fournal of the European Communities 1993;L110/4.5 $1993: 20$. Criteria for classification as car-
cinogenic substances. Official fournal of the European Communities 1993;L110A 4·5 1993:61-2.

6 Council Directive 78/610/EEC of 29 June 1978 on the approximation of the laws, regulations and administrative provisions of the Member States on the protection of the health of workers exposed to vinyl chloride monomer. Official Fournal of the European Communities 1978 L197/22 -7.1978:12-8.

7 Council Directive $82 / 605 /$ EEC of 28 July 1982 on the protection of workers from the risks related to exposure to metallic lead and its ionic compounds at work. Official Fournal of the European Communities 1982, Ofin:23.8.1982:12-21.

8 Council Directive 83/477/EEC of 19 September 1983 on the protection of workers from the risks related to exposure to asbestos at work. Official fournal of the European Communities 1983;L263/24-9-1983:25-32. Council Directive 91/382/EEC of 25 June 1991 amending Directive $83 / 477 / \mathrm{EEC}$ on the protection of workers from the risks related to exposure to asbestos at work. Official fournal of the European Communities 1991;L.206/29・7-1991:16-8.

9 Council Directive 88/364/EEC of 9 June 1988 on the protection of workers by the banning of certain specified agents and/or certain work activities. Official fournal of the European Communities 1988;L179/9・7-1988:44-7.

10 Commission Directive 91/322/EEC of 29 May 1991 on establishing indicative limit values by implementing Council Directive 80/1107/EEC on the protection of workers from the risks related to exposure to chemical, physical, and biological agents at work. Official fournal of the European Communities 1991;L177/5·7·1991:22-4.

11 Commission Decision of 12 July 1995 setting up Scientific Committee for Ocupational Exposure Limits to Chemical Agents. Official fournal of the European Communities 1995;L188/9.8・1995:14-5.

12 Occupational exposure limits. Criteria documents Guidance not EUR 13776. Luxembourg: Official Publications of the European Communities, 1992.

13 Communication from the Commission on a Community programme concerning safety, hygiene, and health at work (1996-2000). (COM(95) 282 final.) Luxembourg: Publications of the European Communities, 1996.

14 Proposal for a Council Directive on the protection of the health and safety of workers from the risks related to chemical agents at work. Official fournal of the European chemical agents at work. Official fournal of the European posal for a Council Directive on the protection of the posal for a Council Directive on the protection of the
health and safety of workers from the risks related to health and safety of workers from the risks related to chemical agents at work. Official fournal

15 Council Directive 89/391/EEC of 12 June 1989 on the introduction of measures to encourage improvements in the safety and health of workers at work Official fourmal of the European Communities 1989;1/183/29.6.1989:1-8.

16 Proposal for a Council Directive amending for the first time Directive $90 / 394 / E E C$ on the protection of workers from the risks related to exposure to carcinogens at work. the risks related to exposure to carcinogens at work. Official fournal of

17 Council Directive 88/379/EEC of 7 June 1988 on the approximation of the laws, regulations, and administrative provisions of the member states relating to the classification, packaging, and labelling of dangerous preparations. Official fournal of the European Communities $1988 ; \mathbf{L} 187 / 16 \cdot 7 \cdot 1988: 14-30$.

\section{Occupational and Environmental Medicine and the electronic age}

OEM has an Email address which is 100632.3615@compuserve.com.We welcome contact by Email, including letters to the editor. Some of our reviewers already send us their reports by Email, helping to speed up the peer review process.

We are moving towards electronic publishing and for some months now we have been asking authors to send us their revised papers on disk as well as a hard copy. I am delighted to report that nearly all our authors are managing to comply with this request. Oddly enough, the few authors who have not sent us a disk version of their revised papers have been almost exclusively from the United Kingdom. I would be interested in suggestions for why this might be. Perhaps United Kingdom based authors read our correspondence and instructions less assiduously? Watch for revised Instructions to Authors.

The Editor 